\title{
Intact cord resuscitation versus early cord clamping in the treatment of depressed newborn infants during the first 10 minutes of birth (Nepcord III) - a randomized clinical trial
}

\author{
Ola Andersson ${ }^{1 *}$ (D) Nisha Rana ${ }^{2}$, Uwe Ewald ${ }^{2}$, Mats Målqvist ${ }^{2}$, Gunilla Stripple ${ }^{3}$, Omkar Basnet ${ }^{4}$, \\ Kalpana Subedi ${ }^{5}$ and Ashish $\mathrm{KC}^{2}$
}

\begin{abstract}
Background: Experiments have shown improved cardiovascular stability in lambs if umbilical cord clamping is postponed until positive pressure ventilation is started. Studies on intact cord resuscitation on human term infants are sparse. The purpose of this study was to evaluate differences in clinical outcomes in non-breathing infants between groups, one where resuscitation is initiated with an intact umbilical cord (intervention group) and one group where cord clamping occurred prior to resuscitation (control group).

Methods: Randomized controlled trial, inclusion period April to August 2016 performed at a tertiary hospital in Kathmandu, Nepal. Late preterm and term infants born vaginally, non-breathing and in need of resuscitation according to the 'Helping Babies Breathe' algorithm were randomized to intact cord resuscitation or early cord clamping before resuscitation. Main outcome measures were saturation by pulse oximetry $\left(\mathrm{SpO}_{2}\right)$, heart rate and Apgar at 1,5 and 10 minutes after birth.
\end{abstract}

Results: At 10 minutes after birth, $\mathrm{SpO}_{2}$ (SD) was significantly higher in the intact cord group compared to the early cord clamping group, 90.4 (8.1) vs 85.4 (2.7) \%, $P<.001$ ). In the intact cord group, 57 (44\%) had $\mathrm{SpO}_{2}<90 \%$ after 10 minutes, compared to $93(100 \%)$ in the early cord clamping group, $P<0.001$. $\mathrm{SpO}_{2}$ was also significantly higher in the intervention (intact cord) group at one and five minutes after birth. Heart rate was lower in the intervention (intact cord) group at one and five minutes and slightly higher at ten minutes, all significant findings. Apgar score was significantly higher at one, five and ten minutes. At 5 minutes, 23 (17\%) had Apgar score $<7$ in the intervention (intact cord) group compared to $26(27 \%)$ in the early cord clamping group, $P<.07$. Newborn infants in the intervention (intact cord) group started to breathe and establish regular breathing earlier than in the early cord clamping group.

Conclusions: This study provides new and important information on the effects of resuscitation with an intact umbilical cord. The findings of improved $\mathrm{SpO}_{2}$ and higher Apgar score, and the absence of negative consequences encourages further studies with longer follow-up.

Trial registration: Clinicaltrials.gov NCT02727517, 2016/4/4

Keywords: Resuscitation, Umbilical cord, Cord clamping, Term newborn, Pulse oximetry, Apgar score

\footnotetext{
* Correspondence: ola.andersson@med.lu.se

'Department of Clinical Sciences Lund, Pediatrics/Neonatology, Skane

University Hospital, Lund University, SUS, Barn- \& Ungdomssjukh. Avd. Ped,

22185 Lund, Sweden

Full list of author information is available at the end of the article
}

(c) The Author(s). 2019 Open Access This article is distributed under the terms of the Creative Commons Attribution 4.0 International License (http://creativecommons.org/licenses/by/4.0/), which permits unrestricted use, distribution, and reproduction in any medium, provided you give appropriate credit to the original author(s) and the source, provide a link to the Creative Commons license, and indicate if changes were made. The Creative Commons Public Domain Dedication waiver (http://creativecommons.org/publicdomain/zero/1.0/) applies to the data made available in this article, unless otherwise stated. 


\section{Background}

Two thirds of a million term newborns die worldwide due to intrapartum-related events, the majority due to asphyxia and a disproportionate amount occurring in low-resource countries [1, 2]. An estimated additional 413,000 infants will develop neonatal encephalopathy after an intrapartum event, resulting in moderate or severe neurodevelopmental impairment. In the Global Burden of Disease 2010 study, intrapartum-related conditions comprised 50.2 million disability adjusted life years [3]. A high priority goal in the global community as recognized by the World Health Organization is prevention of stillborn and newborn mortality; this has resulted in initiatives such as Every Newborn Action Plan [4, 5].

Refined and revised resuscitation guidelines, recommendations, and algorithms during the past decade give health providers evidence-based tools and instructions that may help reduce morbidity and mortality. Adoption and implementation of the International Liaison Committee on Resuscitation (ILCOR) recommendations vary, and initiatives such as Neonatal Resuscitation Program and Helping Babies Breathe have identified the necessity of training and simulation needed to sustain change [6-8].

A non-interventional approach has gained interest and adoption, namely umbilical cord clamping (CC) that is delayed. In a study involving 456 infants, Chaparo et al. could show that by delaying CC until 2 minutes, iron stores were improved at 6 months of age [9]. Furthermore, we have shown that delaying $\mathrm{CC}$ until three minutes is associated with less anemia and improved development at 12 months of age in population in highrisk of iron deficiency and with improved fine motor function and social behavior at 4 years of age in a high income country [10-12]. However, this simple, and costfree evidence-based practice is not widely adopted, although supported by several stakeholders [13].

In most studies, non-vigorous, non-breathing newborns have been excluded. ILCOR recommendations from 2015 states that there is insufficient evidence to recommend an appropriate time for clamping the cord in babies who require resuscitation at birth [6]. The American College of Obstetricians and Gynecologists' Committee on Obstetric Practice declare the need of immediate resuscitation of the newborn to be an indication for immediate cord clamping [14]. In practice, this means that when children are born with reduced vitality, the umbilical cord will be clamped and cut off as soon as possible and the child transferred to a surface prepared for resuscitation, either in the ward or in an adjoining room.

Recent animal experiments have shown if CC occurs before gas exchange of the lung has been established, the physiological circulation can be severely compromised $[15,16]$. These studies have led to proposals for newborns to be resuscitated without clamping the umbilical cord, i.e. resuscitation measures including clearing the airway, stimulating, and, if necessary, ventilation, are initiated while the child still has an intact umbilical cord $[17,18]$.

In humans, the transfused blood from the placenta during the first few minutes can increase overall blood volume with improved cardiac output and better perfusion in both central and peripheral tissues. If placenta circulation is allowed to continue there may be mitigation of the hypoxia, hypoglycemia and acidosis that occurs during a period of asphyxia [19]. An observational study has shown that delayed CC of vital newborn infants resulted in better oxygenation of the blood during the first 10 minutes [20]. A feasibility randomized trial has shown that newborns predicted to be at risk of resuscitation had greater cerebral oxygen at $12 \mathrm{~h}$ of age when $\mathrm{CC}$ was at five minutes compared to $\mathrm{CC}$ within one minute [21].

This area of research is new, and more randomized controlled trials of delayed CC after onset of ventilation are needed to investigate if this practice will result in short-term benefits as well as improved long-term neurodevelopmental outcomes [22]. As the main burden of neonatal mortality due to intra-partum events lies with low resource settings in South Asia and sub-Saharan Africa, we chose to implement our study in Nepal [3].

The purpose of our study was to evaluate differences in clinical outcomes in non-breathing newborns in need of resuscitation between groups, one where resuscitation is initiated prior to $\mathrm{CC}$ (intervention group) compared to a group where $\mathrm{CC}$ occurs prior to resuscitation (control group).

\section{Methods \\ Study design}

We conducted a randomized controlled trial (parallel group study with 1:1 randomization) of pregnancies, finalizing inclusion only after birth of the baby. Ethical approval was obtained from the Nepal Health Research Council, reg. no. 92/2015. Trial registration: Clinicaltrials. gov NCT02727517.

\section{Setting}

The study was performed at the low risk-Maternal and Neonatal Service Centre (MNSC) at Paropakar Maternity and Women's Hospital in Kathmandu, Nepal. Part of the research team had performed an intervention project introducing a simplified algorithm for neonatal resuscitation, Helping Babies Breathe (HBB) at the hospital [23]. The HBB algorithm is routine at the hospital and emphasizes that within the first minute after birth, "The Golden Minute", a baby should breathe or receive positive-pressure ventilation. All babies who do not cry after drying 
should have their airways cleared and receive stimulation to breathe, followed by positive-pressure ventilation if necessary [4]. Before the study all staff underwent a recapitulation of the HBB algorithm including training sessions with the modified algorithm performing intact cord resuscitation. The research team members consisted of trained nurse-midwives with experience in clinical research, five on duty during all hours: one at the antenatal care unit, three at the delivery unit and one at the postnatal care unit. A 10-day training program was provided on selection criteria of women, taking consent, Apgar (including breathing) assessment and placement of the neonatal Masimo@ pulse oximeter probe (Masimo Corporation, Switzerland).

\section{Inclusion and consent}

The hospital criteria for admission to MNSC were: uncomplicated pregnancies, no complication at admission, healthy mothers (no clinical history of hypertension, infection, diabetes, or chronic medical condition), expected vaginal delivery, gestational age between 34 and 41 weeks, and singleton pregnancy.

Women were eligible to participate in the study if they were assigned to MNSC. Mothers admitted to MNSC were informed and asked for consent. Four research team members were present at admission and at the delivery department at all hours and days of the week. Newborns were eligible and included if they had reached a gestational age $\geq 33$ weeks, were in need of resuscitation according to the HBB algorithm, that is: no breathing despite thorough drying and additional stimulation within $30 \mathrm{~s}$ after birth [24]. Newborns not in need of resuscitation were included in a parallel study, Nepcord II [25].

Exclusion criteria: Monochorionic twins (from an ultrasound scan) or clinical evidence of twin-twin transfusion syndrome, triplets or higher order multiple pregnancy, and fetuses with known congenital malformation.

\section{Randomization}

Sequentially numbered, opaque envelopes containing the allocation were prepared by one of the authors (AKC) using a random digit generated list. AKC had no further clinical involvement in the trial.

Randomization was performed as follows: resuscitation with an intact umbilical cord close to the mother in her bed (Fig. 1), or standard care (resuscitation according to the $\mathrm{HBB}$ algorithm including early cord clamping) at a designated area, on a resuscitation table in a room next to the delivery room (Fig. 2). Delay in cord clamping was instructed to be at least $180 \mathrm{~s}$ in the intact cord group. Allocation was decided when birth was imminent, the research team member opened the next opaque numbered envelope and informed the staff managing the delivery on handling strategy of the allocated group.

\section{Blinding}

Due to the nature of the intervention and the close proximity in time to outcome measures, blinding was not possible.

\section{Data collection}

When the child was born, 2-3 research team members collaborated to start a timer, apply a pulse oximetry sensor on the right hand/arm of the newborn infant, and

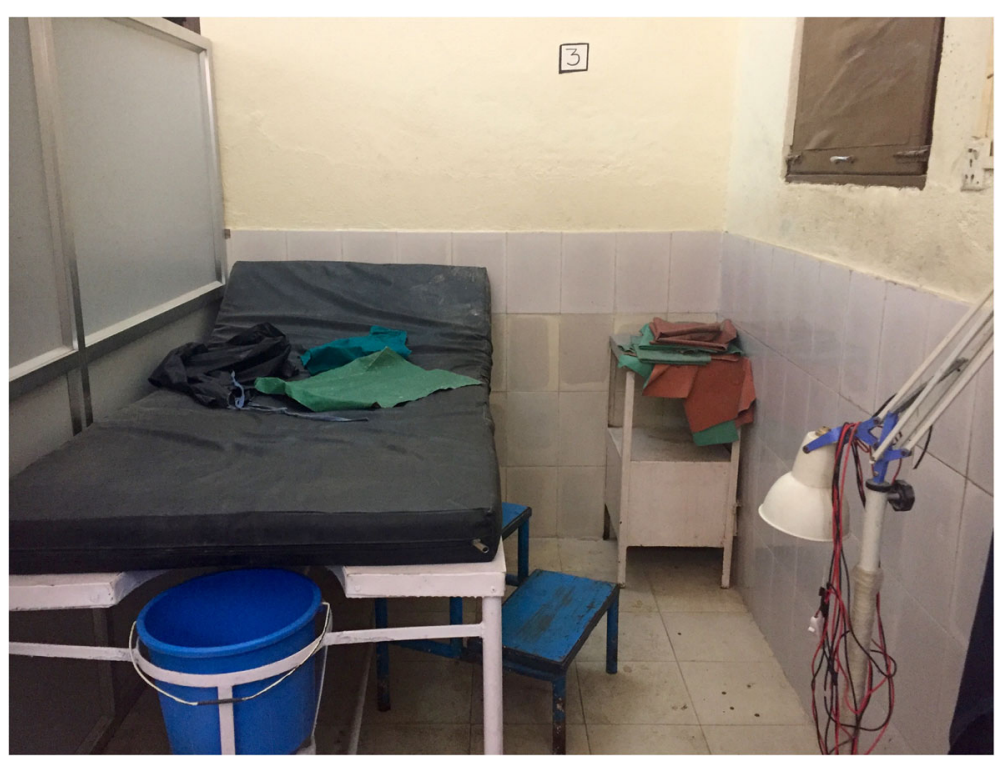

Fig. 1 Image of a bed in the delivery department 


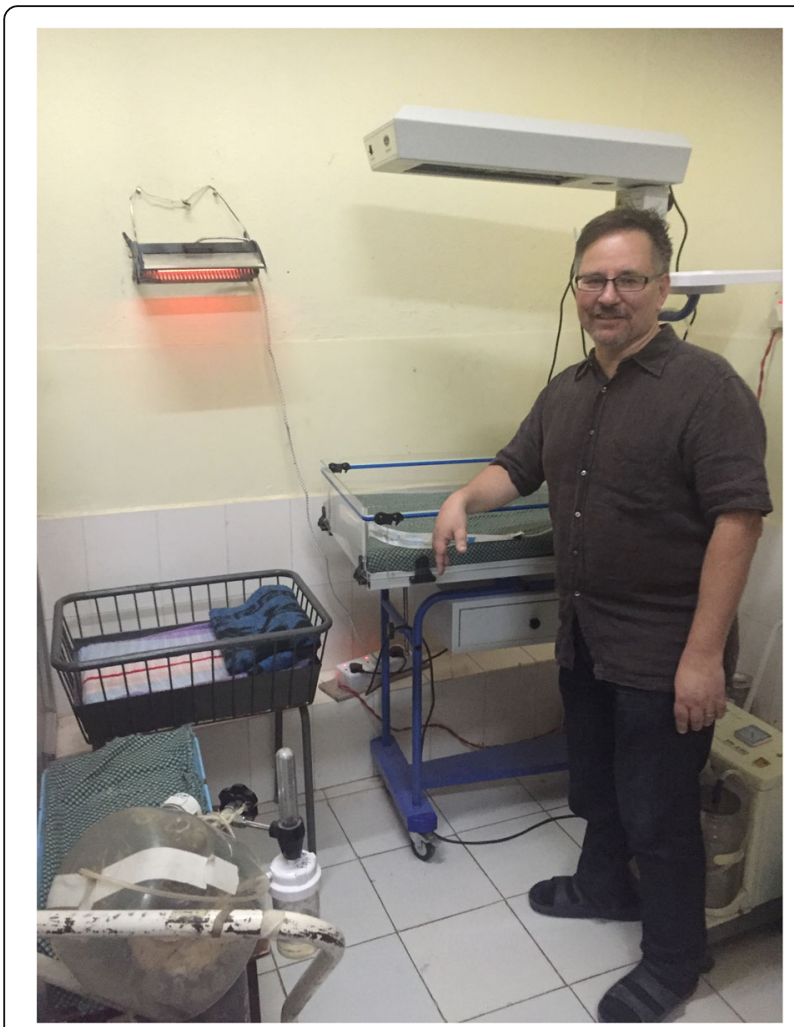

Fig. 2 Image of the resuscitation table in a room next to the delivery room. The corresponding author standing beside it

record time of first breath, time for regular breathing, time for cord clamping as well as Apgar score.

\section{Primary outcome}

Saturation by pulse oximetry $\left(\mathrm{SpO}_{2}\right)$ at $10 \mathrm{~min}$ after birth.

\section{Secondary outcome}

- $\mathrm{SpO}_{2}$ at five minutes after birth

- Time to reach $>90 \%$ in $\mathrm{SpO}_{2}$

- Newborn heart rate at one, five and ten minutes after birth measured by pulse oximeter.

- Apgar score at one, five and ten minutes after birth

- Timing of recorded first breathing effort and established regular breathing

- Rectal temperature at 10-20 min

- Bilirubin at discharge from hospital

- Health status the day after birth (12-36 h after birth) - Alive or deceased

Background information regarding the women and pregnancies were collected from the hospital records by a research team member. All data were transferred to an individual datasheet. Data sheets were checked for quality and stored in a locked room at the hospital until the end of the study. Data were then entered into a database and used for statistical analyses.

\section{Sample size}

A power analysis shows that a group size of 99 would allow us to find a difference of $2 \%$ in $\mathrm{SpO}_{2}$ between groups at 10 minutes after birth with a power of $80 \%$ and a significance level of 0.05 , assuming a mean saturation (SD) of $96 \%$ (5) in the delayed cord clamping group [26]. Allowing for an attrition of $20 \%$, we planned to include 120 participants in each group.

\section{Statistical analysis}

For group comparisons of continuous variables, we used unpaired Student's t-test for variables with normal distribution and Mann-Whitney $U$ test for variables with skewed distribution. Categorical variables were compared between groups using Fisher's exact test.

We calculated the numbers needed to treat, relative risk reduction, and their confidence intervals using the web based JavaStat calculator. A $p$-value $<0.05$ was considered significant.

All analyses were made on an intention to treat basis as prespecified in the study protocol.

We performed all analyses for the primary and secondary outcomes, including only cases handled according to allocation (per protocol). Results are reported in Table 3.

\section{Sensitivity analysis}

To examine if adjusted analysis would yield results different from unadjusted analysis, we analyzed the correlation coefficients between baseline data that was not randomly distributed between treatment groups with primary and secondary outcomes with Spearman's rank correlation.

\section{Auxiliary analysis}

Due to uneven group size after randomization and a large protocol violation rate in the intact cord group, we also chose to do alternate analysis including only infants where resuscitation was performed with bag and mask, reported in Table 4. An ANOVA analysis including posthoc multiple comparisons comparing the infants divided into three groups, intact cord resuscitation per protocol $(\mathrm{C} \geq 180 \mathrm{~s})$, intact cord resuscitation protocol violation $(\mathrm{CC}<180 \mathrm{~s})$ and early $\mathrm{CC}$ was also performed [see Additional file 1].

\section{Results}

From April 20 to August 27, 2016, 1560 women who were admitted to MNSC agreed to participate in the study. After signed consent was obtained and as birth was imminent, 780 women were randomly assigned to 
early cord clamping and 780 to delayed cord clamping where $\mathrm{CC}$ occurred after at least 3 minutes subsequent to the appearance of the infant's shoulder. Of the 1560 included newborns, 1329 were breathing and were excluded, while 231 were assessed as needing resuscitation according to the HBB algorithm (e.g. not crying), 141 boys (61.0\%) and 90 girls (39.0\%); mean (SD) gestational age, 39.6 (1.4) weeks. More infants were assessed as needing resuscitation in the delayed CC group, 134 (17.2\%) compared to $97(12.4 \%)$ in the early CC group. In the power analysis we expected even groups and aimed for a group size of 99 after attrition. The difference was consistent through the recruitment period. The allocated intervention was followed in $65(48.6 \%)$ cases in the intact cord group in contrast to $97(100 \%)$ in the early CC group (Fig. 3). Lowest adherence to protocol in the delayed CC group was in April; 4 cases (25.0\%) and highest in July: 28 cases $(70.0 \%)$ but fell again in August: 6 (33.3\%). Deliveries were distributed with a median (min to max range) of 27 (16 to 40) newborns per fortnight, and evenly throughout the day; 58 (25\%) during the first $6 \mathrm{~h}, 47$ (20\%), during the next six until noon, $57(25 \%)$ the $6 \mathrm{~h}$ after noon and 69 (30\%) last $6 \mathrm{~h}$ until midnight. Clearing of airways was sufficient to achieve normal breathing in 35 (15\%) infants, 74 (32\%) needed stimulation, and bag and mask ventilation had to be performed on 122 (53\%) newborns. The median time to clamping the umbilical cord was 105 (interquartile range, 30-191) seconds for the intact cord group and 25 (interquartile range, 14-40) seconds for the early clamping group $(P<.001)$. Breathing attempts were observed before clamping the cord in 88 (65.7\%) newborns in the intact cord group, compared to $19(19.6 \%)$ in the early CC group, $P<0.001$. We found some significant differences between the delayed and early clamping groups with respect to maternal characteristics: mothers in the intact cord group were slightly older and had a higher mean number of pregnancies. Neither mothers age or number of pregnancies were significantly correlated to any of the primary or secondary outcomes. Neonatal baseline data such as gestational age and birth weight were similar between groups as was presence of meconium stained amniotic fluid (Table 1).

\section{Primary outcome}

At 10 min after birth, oxygen saturation was significantly higher $(5.0 \%)$ in the intact cord group compared to the early CC group (Table 2). In the intact cord group, 57 (44\%) had oxygen saturation $<90 \%$ after $10 \mathrm{~min}$, compared to $93(100 \%)$ in the early CC group, absolute risk reduction 56\% (CI 48-56\%), numbers needed to treat 1.8 (CI 1.8-2.1) (Fig. 4).

\section{Secondary outcomes}

Oxygen saturation was also significantly higher in the intact cord group at one and five minutes after birth. At 5 min, the intact cord group, 70 (54\%) had oxygen saturation $<85 \%$ compared to 85 (91\%) in the early CC group, absolute risk reduction 37\% (26 to $45 \%$ ), $P<.001$, numbers needed to treat 2.7 (CI 2.2-3.9). (Fig. 4).

Heart rate was lower in the intact cord group at one and five minutes and slightly higher at ten minutes, all significant findings (Table 2). Apgar score was significantly higher at one, five and ten minutes. At $5 \mathrm{~min}, 23$ (17\%) had Apgar score $<7$ in the intact cord group compared to $26(27 \%)$ in the early CC group, absolute risk reduction $10 \%$ ( -2 to $21 \%$ ), $P<.07$. (Fig. 4 ).

Time of initiating resuscitation was later in the intact cord group while newborns started breathing and established regular breathing earlier (Table 2). Temperature was measured at mean (SD) 18.0 (7.1) minutes, and there was no difference in temperature between groups. Also, transcutaneous bilirubin measured at discharge did not differ. (Table 2).

In the intact cord group, 16 (11.9\%) newborns were transferred to the Neonatal intensive care unit, not significantly different from $13(13.4 \%)$ in the early CC group, $P=.84$. The mortality rate before discharge was 0 $(0.0 \%)$ in the intact cord resuscitation group versus 3 (3.1\%) in the early CC group, $P=.07$. (Fig. 4).

When analysis was performed including only newborns handled according to protocol, results were similar, or more pronounced (Table 3). Also, when analysis was performed including only those newborns requiring bag and mask resuscitation, results were similar (Table 4). An ANOVA analysis including post-hoc multiple comparisons comparing the infants divided into three groups, intact cord resuscitation per protocol $(C C \geq 180 \mathrm{~s})$, intact cord resuscitation protocol violations $(\mathrm{CC}<180 \mathrm{~s})$ and early $\mathrm{CC}$ did demonstrate that early $\mathrm{CC}$ was similar or disadvantageous compared to the two intact cord resuscitation groups [see Additional file 1].

\section{Discussion}

In this trial, where randomization was performed while the baby was still in utero, resuscitation measures performed according to the HBB algorithm with an unclamped cord in the mother's bed were associated with a higher oxygen saturation and a higher Apgar score at one, five and ten minutes. Breathing was initiated earlier, and no signs of harm were found, when compared to clamping and cutting the cord before initiation of resuscitation measures. In contrast to experimental animal studies, but in congruence with human studies, heart rate was lower at one and five minutes after intact cord, compared to early CC $[15,20]$. A low rate of protocol adherence affects the generalizability of the results. 


\section{CONSORT 2010 Flow Diagram}

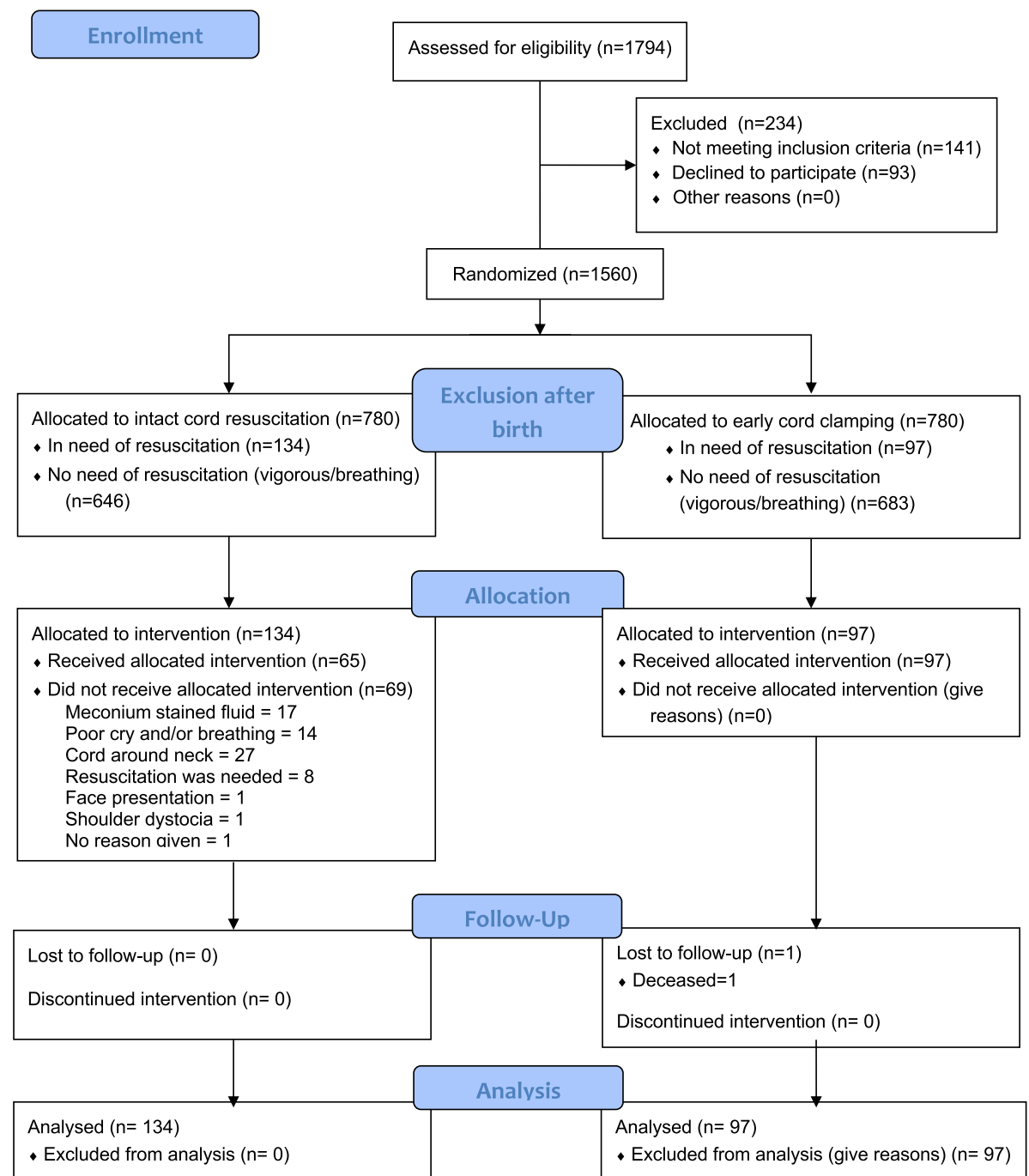

Fig. 3 Trial profile. Flow diagram adapted from the CONSORT flow diagram (http://www.consort-statement.org/)

In their important study on preterm lambs published in 2013, Bhatt et al. could demonstrate a more stable cardiovascular adaptation if cord clamping was performed after initiation of ventilation [15]. In the Bhatt et al. study, heart rate dropped during the first $90 \mathrm{~s}$ if the cord was clamped before ventilating while in our study as well as in the observational study by Smit et al. on human newborns, heart rate was initially lower in the delayed CC group. We hypothesize that a smoother transition ensures a higher blood volume and a larger heart stroke volume, allowing for a lower heart rate with maintained cardiac output. The results from these, and other studies rendered several papers suggesting that resuscitation of newborns should be performed with an uncut cord, facilitating the postnatal transition [17, 18, 27]. The increased oxygenation found in our study may be due to several interacting mechanisms; a persisting oxygenation by the placenta, an increased pulmonary blood flow, earlier initiation of breathing, and an improved perfusion of organs and peripheral tissue including skin and muscles due to optimized blood volume and pressure. To our knowledge, resuscitation with an uncut cord has only been studied in humans in a few studies. Katheria et al. conducted a feasibility study of 60 term newborns that were at risk of resuscitation, randomized to either 1 minute or 5 minute CC [21]. Only $53 \%(n=32)$ actually needed resuscitation but the findings in the study did show greater cerebral oxygenation and blood pressure in the 5-minute group where resuscitation was performed with an intact placental circulation. In concordance to our study, $\mathrm{SpO} 2$ was higher in the 5-minute $\mathrm{CC}$ group, although only significant at three and four minutes in subjects not requiring supplemental oxygen or positive pressure ventilation. Also, time to first breath/cry was 
Table 1 Baseline characteristics of mothers and newborn infants who were randomized to resuscitation with an intact cord (intervention) or after early cord clamping (control)

\begin{tabular}{|c|c|c|}
\hline & \multicolumn{2}{|l|}{ Cord clamping group } \\
\hline & $\begin{array}{l}\text { Intact cord > } 3 \mathrm{~min} \\
(n=134)\end{array}$ & $\begin{array}{l}\text { Early }<1 \text { min } \\
(n=97)\end{array}$ \\
\hline \multicolumn{3}{|l|}{ Maternal characteristics } \\
\hline Maternal age, years ${ }^{a}$ & $23.2(4.1)$ & $22.1(3.5)$ \\
\hline Parity (including study child) ${ }^{\mathrm{b}}$ & $1.5(0.8)$ & $1.3(0.6)$ \\
\hline Vaginal delivery (non-instrumental) & $134(100 \%)$ & 97 (100\%) \\
\hline \multicolumn{3}{|l|}{ Infant characteristics } \\
\hline Gestational age, weeks & $39.6(1.4)$ & $39.6(1.4)$ \\
\hline Male sex & $77(57 \%)$ & $64(66 \%)$ \\
\hline Meconium stained amniotic fluid & $58(43.3 \%)$ & $40(41.2 \%)$ \\
\hline Birth weight, $g$ & $3072(401)$ & $3036(372)$ \\
\hline
\end{tabular}

Data are mean (SD) or $\mathrm{n}(\%)$

a Difference 1.1 years $(95 \% \mathrm{Cl} 0.1-2.1), P$ value $=.03$

${ }^{\mathrm{b}}$ Difference 0.2 children $(95 \% \mathrm{Cl} 0.0-0.4), P$ value $=.02$ similar to our findings, although not significant; mean (SD) 25 (42) in the 5-minute group compared to 36 (61) in the 1minute group [21]. In contrast, Ersdal et al. could not demonstrate any relationship between time to $\mathrm{CC}$ and onset of breathing or initiation of positive pressure ventilation following stimulation/suction, or 24-h outcome in an observational study [28]. In agreement with our results that intact cord resuscitation might be favorable, Lefebvre et al. studied newborns that had in utero congenital diaphragmatic hernia in an observational study, and could demonstrate that an initiation of resuscitation measures before clamping the umbilical cord was associated with higher $\mathrm{pH}$ and lower plasma lactate at $1 \mathrm{~h}$ after birth, as well as higher blood pressure at one, six and $12 \mathrm{~h}$ after birth [29].

Our study suffers from certain limitations. There was a high degree of protocol violation in the intact cord group, and it is possible that the newborns among the protocol violation group were in a more depressed state than those remaining in the intact cord resuscitation group. Prenatal fetal monitoring as well as blood gas sampling from the umbilical cord might have given a better understanding regarding this issue. A separate analysis comparing outcomes

Table 2 Measurements from infants who were randomized to resuscitation with an intact cord (intervention) or after early cord clamping (control). Intention to treat analysis

\begin{tabular}{|c|c|c|c|c|}
\hline & \multicolumn{2}{|c|}{ Cord Clamping Group, Mean (SD) } & \multirow{2}{*}{$\begin{array}{l}\text { Difference } \\
(95 \% \mathrm{Cl})\end{array}$} & \multirow[t]{2}{*}{$P$ value $^{a}$} \\
\hline & Intact cord $>3 \mathrm{~min}$ & Early $<1 \mathrm{~min})$ & & \\
\hline Readings from pulse oximeter & $(n=129)$ & $(n=93)$ & & \\
\hline Saturation at $1 \min (\%)$ & $71.5(9.3)$ & $62.4(4.3)$ & 9.1 (7.3 to 11.0$)$ & $<.001$ \\
\hline Saturation at $5 \min (\%)$ & $83.6(8.3)$ & $76.6(4.1)$ & 7.0 (5.3 to 8.7$)$ & $<.001$ \\
\hline Saturation at $10 \min (\%)$ & $90.4(8.1)$ & $85.4(2.7)$ & 5.0 (3.5 to 6.5$)$ & $<.001$ \\
\hline Heart rate at $1 \mathrm{~min}$ & $105(3)$ & $116(5)$ & $-10(-11$ to -9$)$ & $<.001$ \\
\hline Heart rate at 5 min & $124(4)$ & $134(4)$ & $-10(-11$ to -8$)$ & $<.001$ \\
\hline Heart rate at $10 \mathrm{~min}$ & $136(2)$ & $135(2)$ & $1(0$ to 1$)$ & .03 \\
\hline Apgar score & $(n=134)$ & $(n=97)$ & & \\
\hline Apgar at $1 \mathrm{~min}$ & $5.1(1.0)$ & $4.3(1.0)$ & $0.8(0.5$ to 1.1$)$ & $<.001$ \\
\hline Apgar at $5 \mathrm{~min}$ & $6.8(0.7)$ & $6.5(1.1)$ & 0.3 (0.1 to 0.5$)$ & .01 \\
\hline Apgar at $10 \mathrm{~min}$ & $9.4(1.0)$ & $9.0(1.5)$ & 0.4 (0.2 to 0.7$)$ & .03 \\
\hline Timed events, Median (interquartile range) & $(n=134)$ & $(n=97)$ & & \\
\hline Time of start of resuscitation (sec) & 45 (28 to 68$)$ & 45 (25 to 59$)$ & & $.19^{\mathrm{b}}$ \\
\hline Time of first cry/breath (sec) & 37 (34 to 44$)$ & 45 (38 to 50$)$ & & $<.001^{\mathrm{b}}$ \\
\hline Time of regular breathing $(\mathrm{sec})^{c}$ & 78 (67 to 96$)$ & 98 (89 to 356$)$ & & $<.001^{\mathrm{b}}$ \\
\hline Time to cord clamping (sec) & 104 (30 to 191) & $25(14$ to 40$)$ & & $<.001^{\mathrm{b}}$ \\
\hline \multicolumn{5}{|l|}{ Measurements after resuscitation } \\
\hline Baby's temperature $\left(C^{o}\right)^{d}$ & $36.2(0.5)$ & $36.2(0.5)$ & $0.0(-0.1$ to 0.1$)$ & .82 \\
\hline Transcutaneous bilirubin $(\mu \mathrm{mol} / \mathrm{L})$ at discharge $\mathrm{e}^{\mathrm{e}}$ & $97.8(52.5)$ & $89.1(52.6)$ & $8.6(-5.5$ to 23.0$)$ & .23 \\
\hline
\end{tabular}

${ }^{a}$ Calculated using an unpaired 2-tailed $t$ test

${ }^{b}$ Calculated using Mann Whitney $\mathrm{U}$ test

CIntact cord group $n=132$ and the early group $n=93$

${ }^{d}$ Intact cord group $n=127$ and the early group $n=90$

${ }^{\mathrm{e}}$ Age (hours) at discharge was median (interquartile range) 21.6 (15.4 to 31.6) in the intact cord group ( $\left.n=128\right)$ vs 22.2 (14.5 to 33.9 ) in the early group $(n=95), p=.83$ 


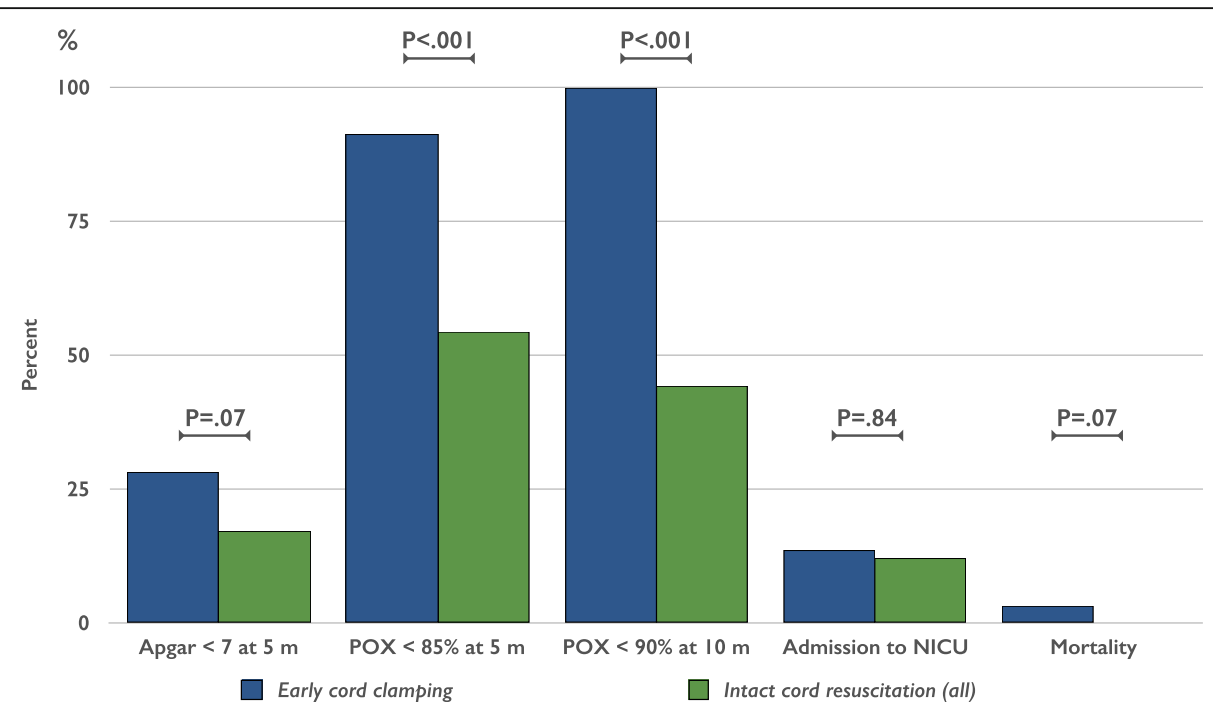

Fig. 4 Outcome on categorical variables after resuscitation with an intact cord versus early cord clamping. $P$-value calculated using Fischer's exact test

Table 3 Measurements from infants who were randomized to resuscitation with an intact cord (intervention) or after early cord clamping (control). Only infants handled according to allocation (per protocol) analyzed

\begin{tabular}{|c|c|c|c|c|}
\hline & \multicolumn{2}{|c|}{ Cord Clamping Group, Mean (SD) } & \multirow{2}{*}{$\begin{array}{l}\text { Difference } \\
(95 \% \mathrm{Cl})\end{array}$} & \multirow[t]{2}{*}{$P$ value } \\
\hline & Intact cord $>3 \mathrm{~min}$ & Early $<1$ min & & \\
\hline Readings from pulse oximeter & $(n=63)$ & $(n=93)$ & & \\
\hline Saturation at $1 \mathrm{~min}(\%)$ & $79.8(3.6)$ & $62.4(4.3)$ & $17.4(16.1$ to 18.7$)$ & $<.001$ \\
\hline Saturation at $5 \min (\%)$ & $91.4(3.1)$ & $76.6(4.1)$ & 14.8 (13.6 to 16.0$)$ & $<.001$ \\
\hline Saturation at $10 \mathrm{~min}(\%)$ & $98.0(1.4)$ & $85.4(2.7)$ & $12.6(11.8$ to 13.3$)$ & $<.001$ \\
\hline Heart rate at $1 \mathrm{~min}$ & $105(3)$ & $116(5)$ & $-11(-12$ to -10$)$ & $<.001$ \\
\hline Heart rate at $5 \mathrm{~min}$ & $125(3)$ & $134(4)$ & $-9(-10$ to -7$)$ & $<.001$ \\
\hline Heart rate at $10 \mathrm{~min}$ & $137(2)$ & $135(2)$ & 2 (1 to 2 ) & $<.001$ \\
\hline Apgar score & $(n=63)$ & $(n=93)$ & & \\
\hline Apgar at $1 \mathrm{~min}$ & $5.7(0.9)$ & $4.3(0.9)$ & $1.4(1.1$ to 1.6$)$ & $<.001$ \\
\hline Apgar at $5 \mathrm{~min}$ & $7.0(0.5)$ & $6.6(0.9)$ & 0.5 (0.2 to 0.7$)$ & $<.001$ \\
\hline Apgar at $10 \mathrm{~min}$ & $9.6(0.7)$ & $9.0(1.3)$ & $0.6(0.2$ to 1.0$)$ & .001 \\
\hline Timed events, Median (interquartile range) & $(n=65)$ & $(n=97)$ & & \\
\hline Time of start of resuscitation (sec) & 40 (22 to 60$)$ & 45 (25 to 59$)$ & & $.62^{\mathrm{b}}$ \\
\hline Time of first cry/breath (sec) & 34 (28 to 39$)$ & 45 (38 to 50$)$ & & $<.001^{\mathrm{b}}$ \\
\hline Time of regular breathing $(\mathrm{sec})^{c}$ & 69 (34 to 399) & 98 (89 to 356 ) & & $<.001^{\mathrm{b}}$ \\
\hline Time to cord clamping (sec) & 192 (188 to 200$)$ & 25 (14 to 40$)$ & & $<.001^{\mathrm{b}}$ \\
\hline \multicolumn{5}{|l|}{ Measurements after resuscitation } \\
\hline Baby's temperature $\left(C^{\circ}\right) 30$ min after birth ${ }^{d}$ & $36.2(0.6)$ & $36.2(0.5)$ & $0.0(-0.2$ to 0.2$)$ & .82 \\
\hline Transcutaneous bilirubin $(\mu \mathrm{mol} / \mathrm{L})$ at discharge $\mathrm{e}^{\mathrm{e}}$ & $94.4(44.1)$ & $89.1(52.6)$ & $5.3(-11.0$ to 21.7$)$ & .52 \\
\hline
\end{tabular}

${ }^{a}$ Calculated using an unpaired 2-tailed $t$ test

${ }^{\mathrm{b}}$ Calculated using Mann Whitney $\mathrm{U}$ test

Intact cord group $n=65$ and the early group $n=93$

${ }^{d}$ Intact cord group $n=64$ and the early group $n=90$

${ }^{\mathrm{e}} \mathrm{Age}$ (hours) at discharge was median (interquartile range) 22.5 (16.2 to 32.1) in the intact cord group ( $\left.n=61\right)$ vs 22.2 (14.5 to 33.9 ) in the early group $(n=95), p=.81$ 
Table 4 Measurements from infants who were randomized to resuscitation with an intact cord (intervention) or after early cord clamping (control), only including those resuscitated with bag and mask

\begin{tabular}{|c|c|c|c|c|}
\hline & \multicolumn{2}{|c|}{ Cord Clamping Group, Mean (SD) } & \multirow{2}{*}{$\begin{array}{l}\text { Difference } \\
(95 \% \mathrm{Cl})\end{array}$} & \multirow[t]{2}{*}{$P$-value } \\
\hline & Intact cord $>3 \mathrm{~min}$ & Early $<1$ min) & & \\
\hline Readings from pulse oximeter & $(n=72)$ & $(n=45)$ & & \\
\hline Saturation at $1 \mathrm{~min}(\%)$ & $73.7(8.8)$ & $62.6(5.0)$ & $11.1(8.2$ to 13.9$)$ & $<.001$ \\
\hline Saturation at $5 \min (\%)$ & $85.6(8.1)$ & $76.1(3.9)$ & $9.4(6.9$ to 12.0$)$ & $<.001$ \\
\hline Saturation at $10 \min (\%)$ & $91.9(7.9)$ & $85.1(2.8)$ & 6.8 (4.4 to 9.3$)$ & $<.001$ \\
\hline Heart rate at $1 \mathrm{~min}$ & $106(3)$ & $115(5)$ & $-10(-11$ to -8$)$ & $<.001$ \\
\hline Heart rate at $5 \mathrm{~min}$ & $124(4)$ & $134(4)$ & $-10(-11$ to -8$)$ & $<.001$ \\
\hline Heart rate at $10 \mathrm{~min}$ & $136(2)$ & $136(2)$ & $1(0$ to 2$)$ & .05 \\
\hline Apgar score & $(n=74)$ & $(n=48)$ & & \\
\hline Apgar at $1 \mathrm{~min}$ & $5.0(1.1)$ & $3.8(1.1)$ & $1.2(0.8$ to 1.6$)$ & $<0.001$ \\
\hline Apgar at $5 \mathrm{~min}$ & $6.7(0.9)$ & $6.0(1.3)$ & 0.7 (0.3 to 1.1$)$ & 0.001 \\
\hline Apgar at $10 \mathrm{~min}$ & $9.2(1.2)$ & $8.3(1.8)$ & 0.9 (0.3 to 1.5$)$ & 0.005 \\
\hline Timed events, Median (interquartile range) & $(n=74)$ & $(n=48)$ & & \\
\hline Time of start of resuscitation (sec) & 48 (30 to 71$)$ & 43 (23 to 57$)$ & & $.06^{\mathrm{b}}$ \\
\hline Time of first cry/breath (sec) & 38 (34 to 45$)$ & 48 (45 to 62$)$ & & $<.001^{\mathrm{b}}$ \\
\hline Time of regular breathing $(\mathrm{sec})^{c}$ & $78(67$ to 155$)$ & 356 (98 to 389$)$ & & $<.001^{\mathrm{b}}$ \\
\hline Time to cord clamping (sec) & 187 (42 to 195$)$ & 25 (11 to 40$)$ & & $<.001^{\mathrm{b}}$ \\
\hline
\end{tabular}

${ }^{a}$ Calculated using an unpaired 2-tailed $t$ test

${ }^{\mathrm{b}}$ Calculated using Mann Whitney $\mathrm{U}$ test

Intact cord group $n=72$ and the early group $n=45$

between the subgroup of infants randomized to intact cord resuscitation that had their cord cut before $180 \mathrm{~s}$ (protocol violators) to the early $\mathrm{CC}$ group could not demonstrate any negative effects in the protocol violator group. An extensive education and training program was performed involving staff and research team members, but this was not enough to avoid protocol violations, even if staff were accustomed to delayed CC after an earlier study at the same hospital [10]. We examined if the protocol adherence rate varied according to hour of the day and by months but could not find any such pattern. Proposed steps for implementing delayed cord clamping have been published [30]. Due to sparse resources regarding post-natal clinical care, the study also lacks clinical data. Data were collected manually from the screen from the oximeter, resulting in a risk for research team members to unconsciously pick a higher number for one group and a lower number for the other. In this study, masking was not possible.

This study provides new and important information on the effects of resuscitation with an intact cord: In the group allocated to having their cord clamped and cut after three minutes, newborns had higher $\mathrm{SpO}_{2}$ and higher Apgar score, and no negative consequences were recorded, similar to reports on preterm infants [31]. Resuscitation with an intact cord do not need investments in advanced equipment, in agreement with other approaches that are less interventional to their character, such as giving ventilation with air instead of $100 \%$ oxygen and caring of low birth weight infants skin to skin [32, 33]. These approaches are especially, but not exclusively, feasible in low resource settings suffering from high perinatal mortality and morbidity [5].

\section{Conclusions}

We conclude that in term infants, resuscitation with an intact umbilical cord did not raise any safety concerns and was associated with a better recovery than routine resuscitation after clamping and cutting the cord, in concordance with experimental studies. Before implementing in recommendations from ILCOR and algorithms as HBB, further studies are needed to verify our findings in settings where more detailed prenatal and postnatal surveillance is possible, as well as including larger numbers to explore the implied effects on decreased admission rate to neonatal care and mortality and to pursue long-term neurodevelopmental follow up.

\section{Additional file}

Additional file 1: ANOVA analysis including post-hoc multiple comparisons comparing the infants divided into three groups, intact cord resuscitation per protocol (CC $\geq 180 \mathrm{~s})$, intact cord resuscitation protocol violaton (CC < $180 \mathrm{~s}$ ) and early CC. (PDF $61 \mathrm{~kb})$

\section{Abbreviations}

CC: Cord clamping; HBB: Helping Babies Breathe, a simplified algorithm for neonatal resuscitation; ILCOR: International Liaison Committee on Resuscitation; MNSC: Maternal and Neonatal Service Centre; $\mathrm{SpO}_{2}$ : Saturation by pulse oximetry 


\section{Acknowledgements}

We thank all research team members for helping us collect the data, as well as RM Kerstin Nordén, RN Lena Nobring and RN Ann-Cathrin Oskarsson for supervising the initiation period of the study. Orientation and demonstration for resuscitation with intact cord was provided for the Nurse midwifes in the same ward by RM Kerstin Nordén, Dr. Dhan Raj Aryal and Dr. Sheela Verma.

\section{Authors' contributions}

AKC and OA had full access to all of the data in the study and take responsibility for the integrity of the data and the accuracy of the data analysis. Study concept and design: OA, NR, UE, MM, GS, OB, KS, AKC. Acquisition of data: NR, OB. Analysis and interpretation of data: $O A, O B, A K C$. Drafting of the manuscript: OA, AKC. Critical revision of the manuscript for important intellectual content: NR, UE, MM, GS, OB, KS. Obtained funding: OA. Administrative, technical, and material support: OA, NR, OB, AKC. Study supervision: OA, NR, AKC. All authors read and approved the final manuscript.

\section{Funding}

This study was supported by grants from the Swedish Society of Medical Research, the Swedish Society of Medicine and the Little Child's Foundation (Sweden). The funders had no involvement in design and conduct of the study; the collection, management, analysis and interpretation of data; neither in the preparation, review, or approval of the manuscript or in the decision to submit the manuscript for publication.

\section{Availability of data and materials}

The datasets used and/or analyzed during the current study are available from the corresponding author on reasonable request.

\section{Ethics approval and consent to participate}

Ethical approval was obtained from the Nepal Health Research Council, reg. no. 92/2015.

\section{Consent for publication}

Figure 2 shows the resuscitation table and the corresponding author standing beside it. Written informed consent for publication of the image was obtained. A copy of the consent form is available for review by the Editor of this journal.

\section{Competing interests}

The authors declare that they have no competing interests.

\section{Author details}

'Department of Clinical Sciences Lund, Pediatrics/Neonatology, Skane University Hospital, Lund University, SUS, Barn- \& Ungdomssjukh. Avd. Ped, 22185 Lund, Sweden. ${ }^{2}$ International Maternal and Child Health, Department of Women's and Children's Health, Uppsala University, Uppsala, Sweden. ${ }^{3}$ Wass Medicin, Lund, Sweden. ${ }^{4}$ Golden Community, Kathmandu, Nepal. ${ }^{5}$ Paropakar Maternity and Women's Hospital, Kathmandu, Nepal.

Received: 25 May 2019 Accepted: 29 July 2019

Published online: 29 August 2019

\section{References}

1. Liu L, Oza S, Hogan D, et al. Global, regional, and national causes of under-5 mortality in 2000-15: an updated systematic analysis with implications for the sustainable development goals. Lancet. 2016;388(10063):3027-35. https://doi.org/10.1016/S0140-6736(16)31593-8.

2. Goldenberg RL, McClure EM. Maternal, fetal and neonatal mortality: lessons learned from historical changes in high income countries and their potential application to low-income countries. Matern Health Neonatol Perinatol. 2015;1 (1):3. https://doi.org/10.1186/s40748-014-0004-z.

3. Lee ACC, Kozuki N, Blencowe $H$, et al. Intrapartum-related neonatal encephalopathy incidence and impairment at regional and global levels for 2010 with trends from 1990. Pediatr Res. 2013;74:50. https://doi.org/10.1038/ pr.2013.206.

4. Niermeyer S, Robertson NJ, Ersdal HL. Beyond basic resuscitation: what are the next steps to improve the outcomes of resuscitation at birth when resources are limited? Semin Fetal Neonatal Med. 2018;23(5):361-8. https:// doi.org/10.1016/j.siny.2018.06.002.
5. Chou D, Daelmans B, Jolivet RR, et al. Ending preventable maternal and newborn mortality and stillbirths. BMJ. 2015;351:h4255. https://doi.org/1 0.1136/bmj.h4255

6. Wyllie J, Perlman JM, Kattwinkel J, et al. Part 7: neonatal resuscitation: 2015 international consensus on cardiopulmonary resuscitation and emergency cardiovascular care science with treatment recommendations. Resuscitation. 2015;95:e169-201. https://doi.org/10.1016/j.resuscitation.2015.07.045.

7. Ades A, Lee HC. Update on simulation for the neonatal resuscitation program. Semin Perinatol. 2016;40(7):447-54. https://doi.org/10.1053/j. semperi.2016.08.005.

8. Niermeyer S. From the neonatal resuscitation program to helping babies breathe: global impact of educational programs in neonatal resuscitation. Semin Fetal Neonatal Med. 2015;20(5):300-8. https://doi.org/10.1016/j.siny.2 015.06.005.

9. Chaparro CM, Neufeld LM, Tena Alavez G, et al. Effect of timing of umbilical cord clamping on iron status in Mexican infants: a randomised controlled trial. Lancet. 2006;367(9527):1997-2004.

10. Kc A, Rana N, Malqvist M, et al. Effects of delayed umbilical cord clamping vs early clamping on Anemia in infants at 8 and 12 months: a randomized clinical trial. JAMA Pediatr. 2017;171(3):264-70. https://doi.org/10.1001/ jamapediatrics.2016.3971.

11. Rana N, Kc A, Malqvist M, et al. Effect of delayed cord clamping of term babies on neurodevelopment at 12 months: a randomized controlled trial. Neonatology. 2018;115(1):36-42. https://doi.org/10.1159/000491994.

12. Andersson $\mathrm{O}$, Lindquist $\mathrm{B}$, Lindgren $\mathrm{M}$, et al. Effect of delayed cord clamping on neurodevelopment at 4 years of age: a randomized clinical trial. JAMA Pediatr. 2015;169(7):631-8. https://doi.org/10.1001/ jamapediatrics.2015.0358

13. Anton $\mathrm{O}$, Jordan $\mathrm{H}$, Rabe H. Strategies for implementing placental transfusion at birth: a systematic review. Birth. 2018. https://doi.org/10.1111/birt.12398.

14. Committee on Obstetric Practice. Committee Opinion No. 684: delayed umbilical cord clamping after birth. Obstet Gynecol. 2017;129(1):e5-e10. https://doi.org/10.1097/aog.0000000000001860.

15. Bhatt $\mathrm{S}$, Alison BJ, Wallace EM, et al. Delaying cord clamping until ventilation onset improves cardiovascular function at birth in preterm lambs. J Physiol. 2013:591(8):2113-26. https://doi.org/10.1113/jphysiol.2 012.250084

16. Polglase GR, Dawson JA, Kluckow M, et al. Ventilation onset prior to umbilical cord clamping (physiological-based cord clamping) improves systemic and cerebral oxygenation in preterm lambs. PLoS One. 2015;10(2): e0117504. https://doi.org/10.1371/journal.pone.0117504.

17. Niermeyer S, Velaphi S. Promoting physiologic transition at birth: reexamining resuscitation and the timing of cord clamping. Semin Fetal Neonatal Med. 2013;18(6):385-92. https://doi.org/10.1016/j.siny.2013.08.008.

18. Katheria AC, Brown MK, Rich W, et al. Providing a placental transfusion in newborns who need resuscitation. Front Pediatr. 2017:5:1. https://doi.org/1 0.3389/fped.2017.00001.

19. Katheria AC, Lakshminrusimha S, Rabe H, et al. Placental transfusion: a review. J Perinatol. 2017;37(2):105-11. https://doi.org/10.1038/jp.2016.151.

20. Smit M, Dawson JA, Ganzeboom A, et al. Pulse oximetry in newborns with delayed cord clamping and immediate skin-to-skin contact. Arch Dis Child Fetal Neonatal Ed. 2014;99(4):F309-14. https://doi.org/10.1136/archdischild-2 013-305484.

21. Katheria AC, Brown MK, Faksh A, et al. Delayed cord clamping in newborns born at term at risk for resuscitation: a feasibility randomized clinical trial. J Pediatr. 2017;187:313-7.e1. https://doi.org/10.1016/j.jpeds.2017.04.033.

22. Lakshminrusimha S, Van Meurs K. Better timing for cord clamping is after onset of lung aeration. Pediatr Res. 2015;77(5):615-7. https://doi.org/10.103 8/pr.2015.23.

23. Ashish KC, Malqvist M, Wrammert J, et al. Implementing a simplified neonatal resuscitation protocol-helping babies breathe at birth (HBB) - at a tertiary level hospital in Nepal for an increased perinatal survival. BMC Pediatr. 2012;12:159. https://doi.org/10.1186/1471-2431-12-159.

24. World Health Organization. Guidelines on Basic Newborn Resuscitation. Geneva: World Health Organization; 2012; 61. Available from: https://www. who.int/maternal_child_621_adolescent/documents/basic_newborn_ resuscitation/en/.

25. KC A, Singhal N, Gautam J, et al. Effect of early versus delayed cord clamping in neonate on heart rate, breathing and oxygen saturation during first 10 minutes of birth - randomized clinical trial. Matern Health Neonatol. Perinatol. 2019;5(1):7. https://doi.org/10.1186/s40748-019-0103-y. 
26. Dawson JA, Kamlin COF, Vento M, et al. Defining the reference range for oxygen saturation for infants after birth. Pediatrics. 2010;125(6):e1340-e7. https://doi.org/10.1542/peds.2009-1510.

27. Mercer JS, Erickson-Owens DA. Is it time to rethink cord management when resuscitation is needed? J Midwifery Womens Health. 2014;59(6):635-44. https://doi.org/10.1111/jmwh.12206.

28. Ersdal HL, Linde J, Auestad B, et al. Timing of cord clamping in relation to start of breathing or ventilation among depressed neonates-an observational study. BJOG. 2016;123(8):1370-7. https://doi.org/10.1111/14710528.13778.

29. Lefebvre C, Rakza T, Weslinck N, et al. Feasibility and safety of intact cord resuscitation in newborn infants with congenital diaphragmatic hernia (CDH). Resuscitation. 2017;120:20-5. https://doi.org/10.1016/.j.resuscitation.2 017.08.233.

30. McAdams RM, Backes CH, Hutchon DJ. Steps for implementing delayed cord clamping in a hospital setting. Matern Health Neonatol Perinatol. 2015; 1:10. https://doi.org/10.1186/s40748-015-0011-8.

31. Knol R, Brouwer E, Vernooij ASN, et al. Clinical aspects of incorporating cord clamping into stabilisation of preterm infants. Arch Dis Child Fetal Neonatal Ed. 2018;103(5):F493-F7. https://doi.org/10.1136/archdischild-2018-314947.

32. Saugstad OD. Delivery room management of term and preterm newly born infants. Neonatology. 2015;107(4):365-71. https://doi.org/10.1159/000381159.

33. Moore ER, Anderson GC, Bergman N, et al. Early skin-to-skin contact for mothers and their healthy newborn infants. Cochrane Database Syst Rev. 2012;(5):CD003519. https://doi.org/10.1002/14651858.CD003519.pub3.

\section{Publisher's Note}

Springer Nature remains neutral with regard to jurisdictional claims in published maps and institutional affiliations.

Ready to submit your research? Choose BMC and benefit from:

- fast, convenient online submission

- thorough peer review by experienced researchers in your field

- rapid publication on acceptance

- support for research data, including large and complex data types

- gold Open Access which fosters wider collaboration and increased citations

- maximum visibility for your research: over $100 \mathrm{M}$ website views per year

At BMC, research is always in progress.

Learn more biomedcentral.com/submissions 